TM-1496

\title{
Injection Septum Magnets for the Loma Linda Medical Accelerator*
}

\author{
John A. Satti \\ Fermi National Accelerator Laboratory \\ P.O. Box 500, Batavia, Illinois 60510
}

September 22, 1987

*Presented at the 10th International Conference on Magnet Technology (MT-10), Boston, Massachusetts, September 21-25, 1987 


\section{Abstract}

The injection beamline runs over the last magnet before a long straight section and is then displaced downward $55.88 \mathrm{~cm}$ to the accelerator beam- line. The displacement is magnetic and the final deflection onto the synchrotron orbit is by an electric kicker. The first component, the reverse septum magnet, bends the injection beam $25^{\circ}$ downward. This is followed by the injection septum (200 bend upward) and the final injection kicker ( $5 \circ$ bend upward).

The septum magnets produce a peak field of $3.4 \mathrm{~K}$ gauss at a current of 28,000 amperes within a 0.1 msec long pulse. The electric kicker produces a field of $7.3 \mathrm{KV} / \mathrm{cm}$ with a pulse length of 0.0011 msec. The septum magnets are similar to each other in construction with a bending radius of $72.7 \mathrm{~cm}$. The curvature is required to increase the effective aperture. Bach wagnet has a single-turn copper coil bonded to a stainless steel plate for reinforcement. This eliminates insulating material, which could be subject to radiation damage, at the septum. The stainless steel plate is welded to the magnet laminations. The current is confined to the septum by the insulation between the laminations, which are a standard core material. The total septum thickness with shield is $1.27 \mathrm{~cm}$. Pulsing the magnet eliminates the need for water cooling.

\section{Introduction}

Experience obtained from the operation of the pulsed septum magnets in the Fermilab Antiproton Source [1] was used to design the injection septum magnets described in this report. These septa will be used in the proton accelerator for the Loma Linda University Proton Therapy Facility.

These magnets are designed to produce a peak field of $3.4 \mathrm{~K}$ gauss with a bending radius of 72.7 em. This will give an inflection system with injection energy of $3 \mathrm{MeV}$. Initially, a smaller aperture was used, but further beam studies showed that a good field aperture of $10 \mathrm{~cm} \times 5$ ca was required for the injected beam. Field calculations were made [2], and Fig. 1 shows the required septum cross section to obtain a field quality of $\Delta \mathrm{B} / \mathrm{B}= \pm$ $0.05 \%$ over the required aperture.
Injection septum magnets are usually critical components in accelerator systems. In this synchrotron, which is approximately $6 \mathrm{~g}$ in diameter, the beam injection location has very tight geometrical constraints. With the $10 \mathrm{~cm}$ magnet gap, a total septum thickness of $1.27 \mathrm{~cm}$ was necessary to operate within safe working stresses. This required production of a curved septum to aroid losing approximately $2.1 \mathrm{~cm}$ of aperture sagitta. Fig. 2 shows the injection beam geometry in the accelerator long straight section. In between the ring magnets, very little room is available for clearances between the rarious components. The injection septum and the electric kicker are both housed in a common vacuum chamber with final independent alignment adjustments for each one.

Pulsing the magnet eliminates the need for water-cooling the thin copper septum. However, the conductors undergo strong repelling cycling forces which lead to rupture caused by fatigue if not rigidly fixed. Explosion-clad metal consisting of $0.32 \mathrm{~cm}$. OFHC copper clad to $0.85 \mathrm{~cm} 304$ stainless steel is used to enhance the mechanical strength.

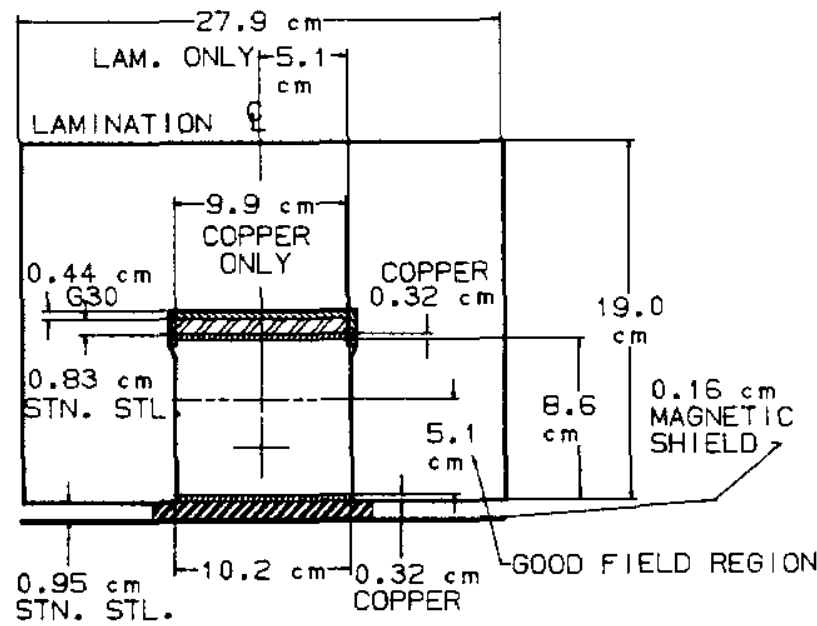

Fig. 1 Injection Septum Magnet Cross Section

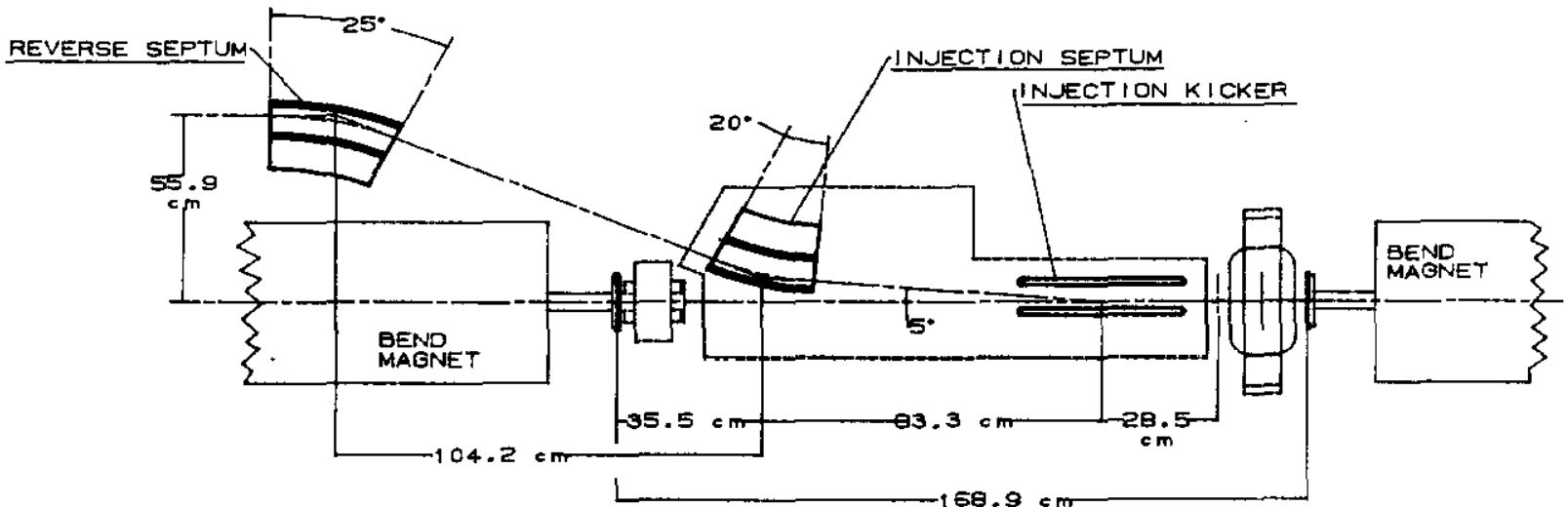

* Operated by the Universities Research Association,

Fig. 2 Injection Beam Geometry

Inc., under contract with the U.S. Depart. of Energy. 
The septum magnets are similar to each other in design. They both produce a peak field of $3.4 \mathrm{~K}$ gauss. The bending length of the reverse septum is $31.75 \mathrm{~cm}$ and $25.4 \mathrm{~cm}$ for the 200 bend injection septum. The cross section of the injection septum magnet is shown in Fig. 1. The total septum thickness is made up of three components: 1) a copper bus carrying a pulsed current of 28,000 amp, 2) a stainless steel plate metallurgically bonded by explosive cladding to the copper, 3) a low-carbon steel plate to shield the circulating beam magnetically. The inner conductor is also bonded to a stainless steel reinforced plate. This composite laminate is electrically insulated to the lamination with a $0.4 \mathrm{~cm}$ thick G-30 channel. The cross section of the injection septum and the electric kicker enclosed in a common vacuum box are shown in Fig. 3. The rough alignnent is made from the enclosure supports. Each component has independent fine adjustment made inside the box through the flange openings. The electric kicker has a fixed botton electrode which is the cathode. The top electrode is adjustable using metal shims to accommodate the injected beam size. The injection septum is closer to the circulating beam. The magnet is supported at three places using alumina ceramic balls. An isometric sketch (Fig. 4) shows the magnet support. Vertical rotation and trist adjustments, about the fixed ball, can be ade by inserting or removing metal shims under the bolt connections. The septum will need fine adjustments to fit between the circulating beam and the injected beam for minimum beam losses. At the crossover connection near the circulating beam, the coil is extended, keeping the copper surface constant between the septum and the inner conductor to minimize end-field effects. The crossover conductors are also bonded to stainless steel support plates. At the septum, the stainless steel plate is welded to the core giving a good rigid construction.

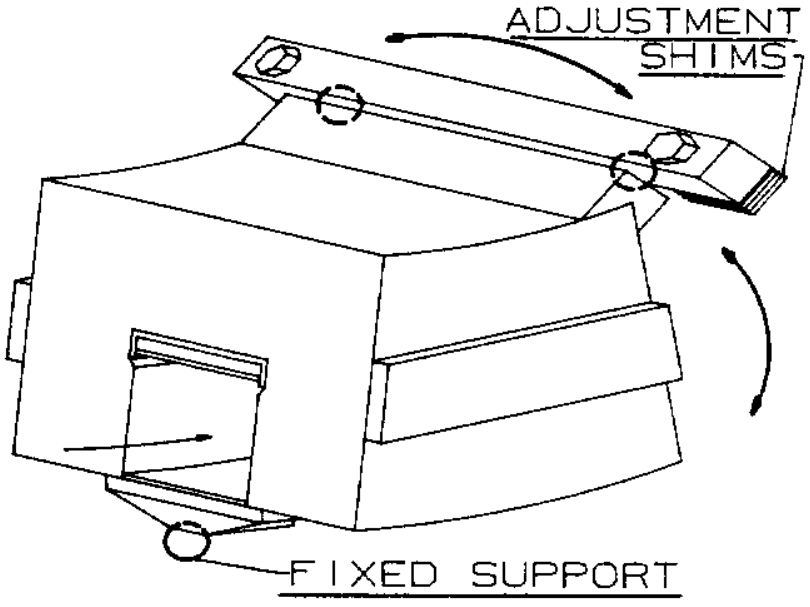

Fig.4 Injection Septum Magnet Support and Adjustment System

Since the laminations are insulated from each other by the core material, the current is constrained to flow along the septum, mostly on the skin of the copper inner surface. The low-carbon steel plate extend past the connection to minimize the fringe field outside the septum at the end. The porer connections to the magnet are symmetrical to the gap center line and are clamped to the core with a ceramic block. The composite laminate is used all the way to the power feedthrus. The inner conductor is insulated frow the core, and the nagnet assembly is constrained within the three aluminum ceramic balls; therefore, the nagnet is electrically insulated to the vacuun box.

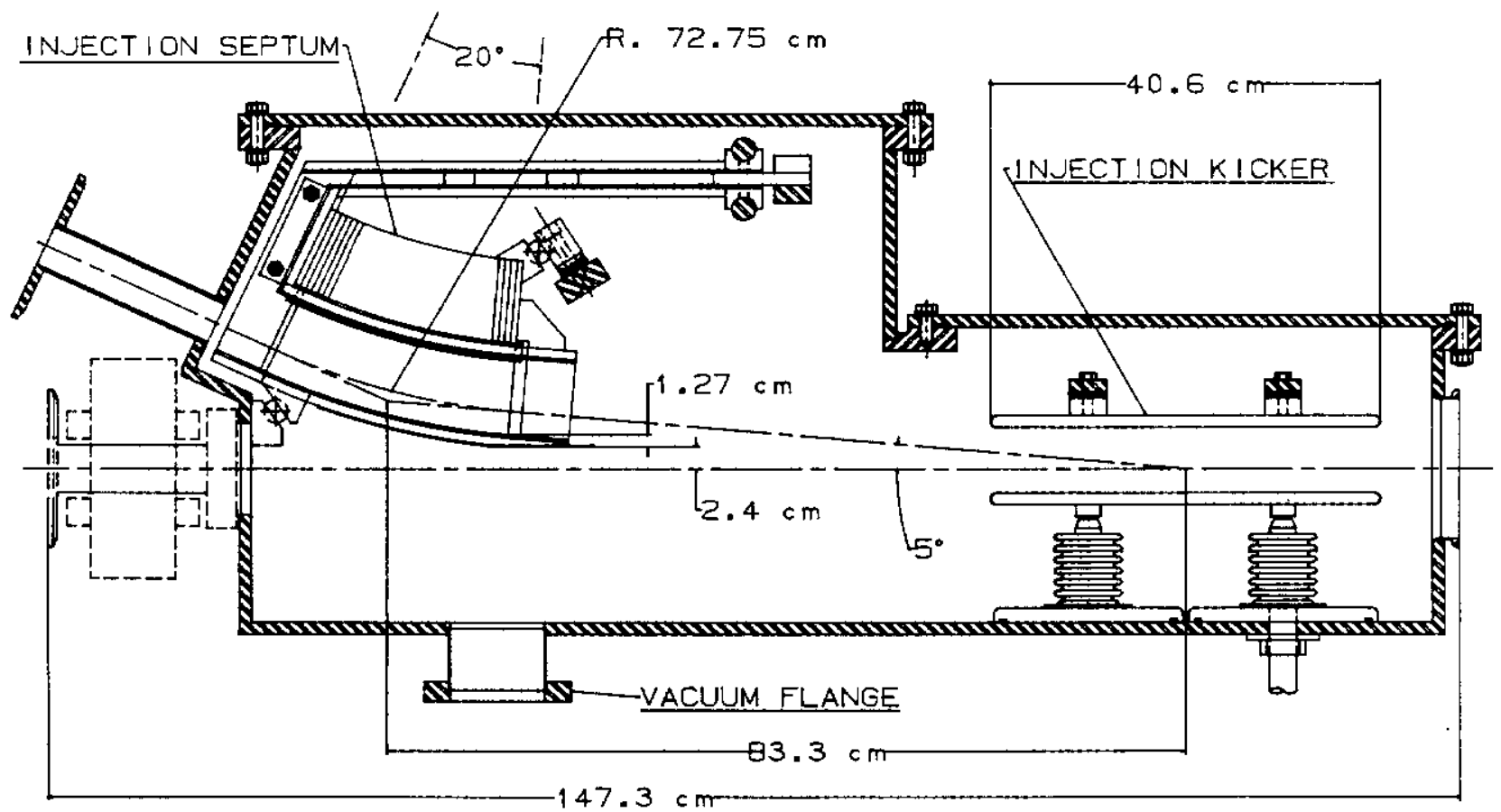

Fig. 3 Injection Septum and Kicker Assembly 
The power leads are clamped with ceramic insulator spacers to constraint the repelling forces from the high current. The cantilever design of the lead assembly will allow small magnet adjustments with linited forces exerted to the power feedthrus.

An average vacuum of $10^{-7}$ torr is required. The vacuum box is made from 316L stainless steel wich has been vacuum degassed. The only organic material that $w i l l$ be exposed to the vacuum will be the G-30 insulation in the magnet and 0 -ring in the flanges. The laminations used in the magnet core will also be vacuum degassed at high temperature before stacking. Before final installation the core assembly will be baked in a vacuum. Outgassing from the magnet assembly is estimated at about $1.5 \times 10^{-5}$ torrliter $/ \mathrm{Cm}^{2} \mathrm{sec}$. An additional pump of $140 \mathrm{l} / \mathrm{sec}$ is installed at the injection vacuum enclosure.

\section{Lamination and Core}

The magnet laminations were punched from a 0.35 mm electrical steel type $\mathbf{M}-22$. The required tolerances in the ap are $+0.03 \mathrm{~mm}$. The surface is coated with a phosphate insulation, resistance AISI c-4. Because the magnet is in a 10-7 torr vacuum, the laminations are vacuum baked at $780 \circ \mathrm{C}$ and degassed for two hours. This baking process removes residual gasses trapped in the netal during fabrication.

The core is assembled by stacking laminations on a curved fixture. Under compression, steel plates are welded on the side of the laminations to hold the core together. The core is then machined to a pie shape. The face of the core is aachined to the required curvature for welding the septum composite assembly. Before final coil assembly, the core is baked to remove any contamination obtained during machining.

\section{Coil and Assembly}

The magnet is designed to be pulsed once every two seconds. A rectangular pulse with a characteristic frequency of $5000 \mathrm{~Hz}$ will be used to drive the current through the magnet. Taking into account the skin effect, an average porer of only 5.8 watts is dissipated in the coil. Cooling is provided by conduction mostly though the copper feedthru rods. Some heat will be conducted through the ceramic ball supports to the skin of the vacuum chamber. The power connection bus terminals will be water cooled. Assuming all the heat to be conducted through the copper bus, a temperature grandient of $12 \circ \mathrm{C}$ was calculated for the coil's extreme points.

In the $3.4 \mathrm{~K}$ gauss field region, the cycling force on the conductor is $96300 \mathrm{~Pa}$. It is this repetitive force that can cause fatigue rupture in the copper conductor and voltage breakthrough from abrasive damage to the insulation. Stainless steel backing bonded to the copper and rigid clamping are the solutions to the cycling force problew. The copper conductor is metallurgically and uniformly bonded to the stainless steel support plate by the explosive-cladding process. This was found to be the best method of obtaining uniform bonding of the two metals. The clad material is purchased in plates to the desired metsl thickness. Parts for the coil are cut, bent, and machined to shapes. At the corners, TIG welds are used to weld the metals. Full penetration fillet welds are used for the copper.

The G-30 insulation channel is first inserted in the core and expoxied in place. Final machining for a saug $\mathrm{fit}$ with the inner conductor is then made. The inner conductor, machined, and with the ends already welded on, is then installed and epoxied inside the insulating channel. The copper surface of the inner conductor is then machined to a tighter tolerance of $\pm 0.05 \mathrm{~mm}$ in the bending radius and $\pm 0.04 \mathrm{~mm}$ to the core gap. These dimensions are critical for obtaining the good-field aperture quality. The septun conductor is finally clamped to the machined face of the core and welded. Maximum accumulating tolerances of $\pm 0.1 \mathrm{~mm}$ are required. These tolerances were achieved with existing operational septum magnets.

\section{Injection Septum Magnet Parameters}

$\begin{array}{lc}\text { Maximum Field (for } 3 \mathrm{MeV} \text { ) } & 3.4 \mathrm{~K} \text { gauss } \\ \text { Bending Radius } & 72.7 \mathrm{~cm} \\ \text { Bending Angle } & 200 \\ \text { Magnet Length } & 25.4 \mathrm{~cm} \\ \text { Aperture Width } & 10 \mathrm{~cm} \\ \text { Aperture Height } & 8.25 \mathrm{~cm}\end{array}$

Septum Thickness at Injection

$\begin{array}{lc}\text { Copper } & 0.32 \mathrm{~cm} \\ \text { Stainless Steel Backing } & 0.79 \mathrm{~cm} \\ \text { Magnetic Stield } & 0.16 \mathrm{~cm} \\ \text { Total Thickness } & 1.27 \mathrm{~cm} \\ & \\ \text { Pulsed Current } & 28,000 \AA \\ \text { Rectangular Pulse } & \\ \text { Characteristic Frequency } & 5000 \mathrm{~Hz} \\ \text { Pulse Interval } & 2 \mathrm{sec} \\ \text { Pulse Duration } & \leq 100 \mu \mathrm{sec} \\ \text { Coil Arerage Power } & 5.8 \mathrm{~W} \\ \text { Pressure on Conductor } & 96,300 \mathrm{~Pa}\end{array}$

\section{Sumary}

Pulsing septum aagnets eliminate the need for water cooling. The fatigue problems from the cycling magnetic forces can now be overcome by using clad materials to reduce fatigue stresses in the conductors. Rigid fastening is important to minimize insulator material wear.

\section{Acknowledgement}

I wish to thank D. Schmitt for drawing the detail design.

\section{References}

[1] J.A. Satti and S.D. Holmes, A pulsed Septum magnet for the Fermilab Antiproton Source, "IEEP Trans. Nucl. Sci., Vol. NS32, pp 3628, Dct. 1985 .

[2] S.C. Snowdon, "Injection Septum Field Calculations", Fermilab LL256 Report. 